\title{
STOP SHARING INFORMATION, DAMMIT! YOU’RE NOT HELPING!
}

\author{
BARRY RICE • Center for Plant Diversity • University of California • Davis • California 95616 • USA \\ -barry@sarracenia.com
}

Keywords: Poaching, field observations.

\section{Introduction}

Friend and colleague Leo Song always had, in his emails, a sig file tag line that read, "Knowledge is not knowledge unless it is shared." He referred to it as his tao. It's an admirable core value-one that we would no doubt benefit to follow more than we do. But there are times....there are times it doesn't work!

The problem is this. There are many people visiting carnivorous plant sites. It's a wonderful experience-both scientifically fascinating and spiritually recharging. A natural consequence is that they want to share news of what they have done. Sadly, this can have very unfortunate consequences. It can both excite poachers and tell them exactly where to go (Figs. 1-3).

Here we are, in 2019, and unquestionably, the poachers are still very, very active.

Below I give five steps that we can take to contribute to a solution, and not be part of the problem. Most of what I am going to say below applies to my experiences in the USA, but I bet that the lessons are exportable across much of the planet. I anticipate some of you might think I could be giving guidance to would-be poachers, but I assure you - they already know everything I describe below. Don’t fool yourself by thinking otherwise.

\section{1) Be VERY careful of sharing site location}

I have had the privilege of visiting carnivorous plant sites scattered across the continent. While many are sites I found myself, I've also been told about others by countless friends-including but not limited to Amorim, Barnes, Brittnacher, Casper, Collingsworth, Determann, Evans, Fleischmann, Fowler, Galloway, Gibson, Hartwell, Howlett, Hummer, Jorge, Lowrie, Mann, Mazrimas, Mazur, McPherson, Miller, Novak, Pagoulatos, Prothero, Rondeau, Schlauer, Schnell, Todd, Tryon,
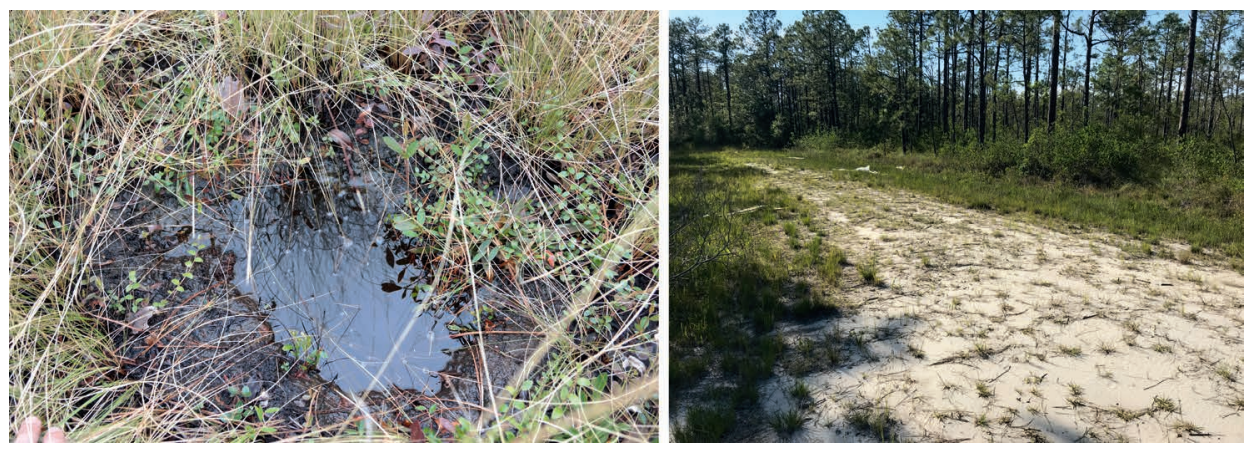

Figure 1: Left: What used to be Sarracenia flava (Pender County, North Carolina), shortly after its location was posted on iNaturalist. Right: This dead-end end road was lined with a population of Sarracenia flava var. atropurpurea. This is what remains (Brunswick County, North Carolina). Photos: Tyler Gramley. 

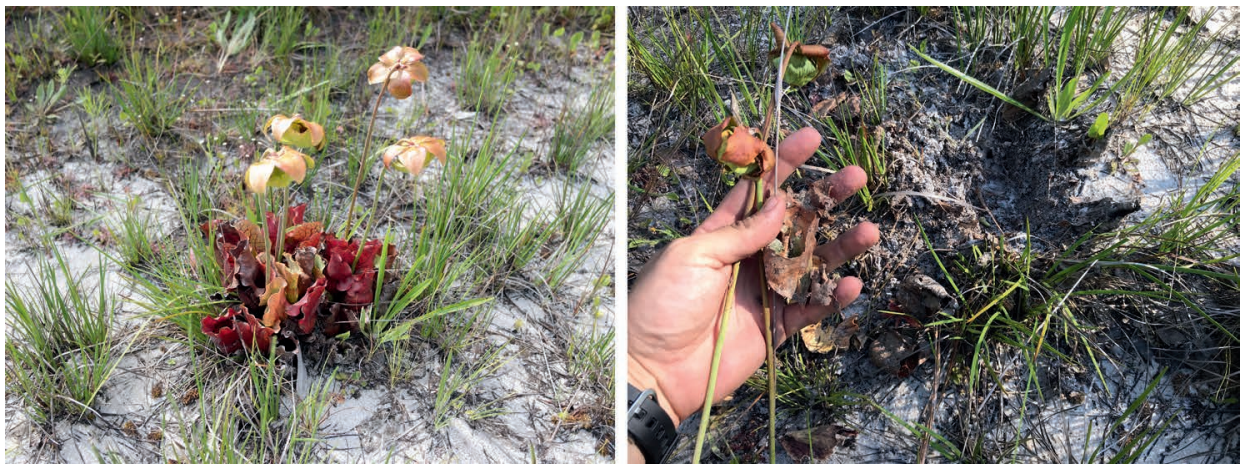

Figure 2: Two images of the same clump of Sarracenia purpurea (Brunswick County, North Carolina), separated by 33 hours. Photos: Tyler Gramley.

Yin, Zerr, and Ziemer; and then of course all my colleagues in academia, NGOs, State, and Federal agencies.

Since I have some prominence, I am frequently contacted by people I barely know, and am asked about sites to visit. Shouldn't I pay forward the kindness shown to me by others? I would love to, but I don't. Unless I have been out in the field with someone, so I can take their measure, I only share information to the highest profile locations.

This is frustrating for everyone. Sometimes folks walk away feeling offended or even insulted. I am sorry, but I am not making a judgement about you (and I am pointing my finger right at you); instead, I am making a judgement about YOU (now, I'm waving my arms in the general direction of humanity). I know that there are some people out there who cannot be trusted.

I have been accused of elitism or of selfishness. I am willing to take on that mantle, if it helps protect the sites and their plants.

\section{2) Be careful of what hard data you share}

Finding carnivorous plant sites can be very

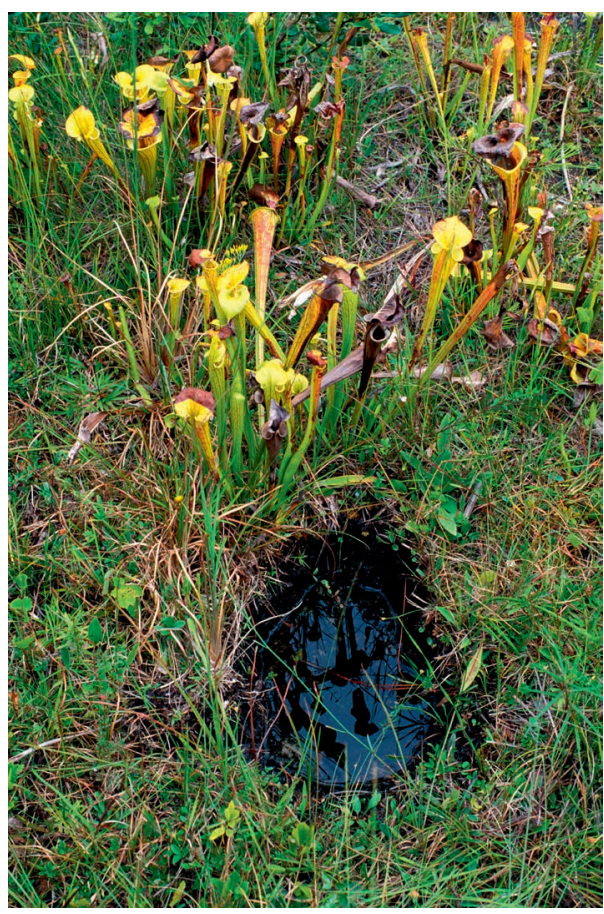

Figure 3: A Sarracenia flava poaching hole (Onslow County, North Carolina). Photo: Barry Rice. easy. There are many places that are set up with boardwalks, visitor centers, and other facilities making the sites perfect for visitation. Information about these can be located within five minutes by anyone with access to the web-I even list some on the FAQ on my Sarracenia.com domain.

In contrast, finding the more obscure places can take a great deal of effort. Indeed, locating carnivorous plant sites in the western USA and documenting them is one of my primary research efforts. It is huge fun and incredibly satisfying. 
As part of my work, I document my results and quietly store them in appropriate scientific data repositories for future botanists. But I enjoy this work so much I want to tell others about what I have seen! So, I often make videos of the sites, which I post online. I am no Stanley Kubrick, so my videos are remedial at best, but I hope that my (tiny) audience enjoys them. I also post my images on my web domain, and also on CalPhotos (calphotos.berkeley.edu). But note-I never post location information with my photographs or videos. At most I give the site's state and county (or parish-yes, Louisiana, I'm looking at you!)—nothing more.

Folks - please do not provide detailed information in your online postings. Yes, your friends are reading your posts, but so are the damned shadowy ghouls who travel with baggies and shovels.

\section{3) Avoid unintended disclosures in group scientific activities}

Group scientific endeavors can be very useful - the Audubon Society has been conducting "Christmas Bird Counts" since 1900, and the resulting data products are no doubt valuable reservoirs of information. More recently, other community-fed data products are becoming popular, probably most notably iNaturalist. This app allows field users to upload information about any organism they encounter in the field. Unfortunately, this tool has great potential for poachers. Indeed, Tyler Gramley (plant administrator with the North American Sarracenia Conservancy) — who has logged many hours looking for carnivorous plants in the field - believes firmly that this app has directly contributed to poaching at many sites, "When an observation on iNaturalist is left unobscured for any period of time, the site will have visible signs of visitation and damage....All of which occur in the short timeline of the day, or within one day, in the wake of an observation." While the culpability of this one app cannot be unquestionably proven, its users should show common sense. There are features on the app that allow the user to blur the precision by which the detailed location information is being reported.

As I write this, I am discussing these issues with staff at iNaturalist. I would like to set the defaults of most carnivorous plants in the USA and Canada to always be blurred. At least, this is my goal-I do not know if they will be interested in complying.

4) Avoid unintended disclosures by image metadata

Handheld electronics (phones, etc.) gather GPS data whenever you take a photo, and encode this GPS information in the metadata for the images. This can be useful when organizing your image sets. However, it can also be transmitted to other recipients if you send them the images. If you have an iPhone, you can change the default setting so GPS metadata is not stored on your images. As I write this, the instructions are simple:

-Open the Settings app on your iPhone;

-Go to the Privacy setting;

- Tap Location Services, then find Camera in the list of apps;

- On the options associated with Camera, select the NEVER or OFF setting.

Androids and other phones have comparable options. Research them and implement them. Now.

During the field trips that were part of the 2018 ICPS Conference in California, before we all ventured out into the field, Gina Morimoto coached all of us on how to turn off the location-encoding on our phones. Everyone was appreciative and understanding of this protocol.

I have experimented with transmitting location-encoded images, and have found that when I upload images to Facebook or transmit images via Facebook Messenger, the GPS data are stripped off. Meanwhile, if I text an image to someone, the GPS data are retained. I do not know if these results are universal- the best approach is to control the Location Services on your phone directly. 
5) Finally, be a snitch (within reason)

Technology is constantly changing. We have not fully adapted to our information revolution. As such, well-meaning people are doing foolish things. If you are associated with an informationproviding agency such as an herbarium, resist the urge to upload all the data you can to the Internet. Sensitive data, even for species without state or federal listing status, should be blurred before being uploaded.

If you see someone else uploading data that should be removed contact the data source immediately.

On the other hand, if you see anyone poaching carnivorous plants, I encourage you to proceed extremely carefully if you contemplate confronting them. I have been told by agency staff in North Carolina that some Dionaea poachers are heavily armed, and I have been advised - if I encounter poachers - to not attempt to engage with them or even photograph them or their vehicles. They are potentially highly dangerous.

If you have gone through all the hard work to sleuth, deduce, and locate a wonderful site - and have the scratches, muddy boots, and torn pants to prove it - good for you. Now work hard to make sure your experience does not come at the expense of the plants you love so much. There will always be poachers out there. I have resigned myself to that. So, ensure that the wonders you experienced by visiting an exquisite plant site do not result in a biological crime by someone else. Try to live in such a way so that the plants and sites you visited, benefitted by your presence.

So maybe, don't share all the knowledge you have. Show discretion.

Sorry, Leo.

The author would like to thank the vigorous, dedicated, and active online community of botanists and naturalists who are working so hard to protect these plants. Tyler Gramley has been invaluable in giving me perspective on some of the risks involved with data-sharing.

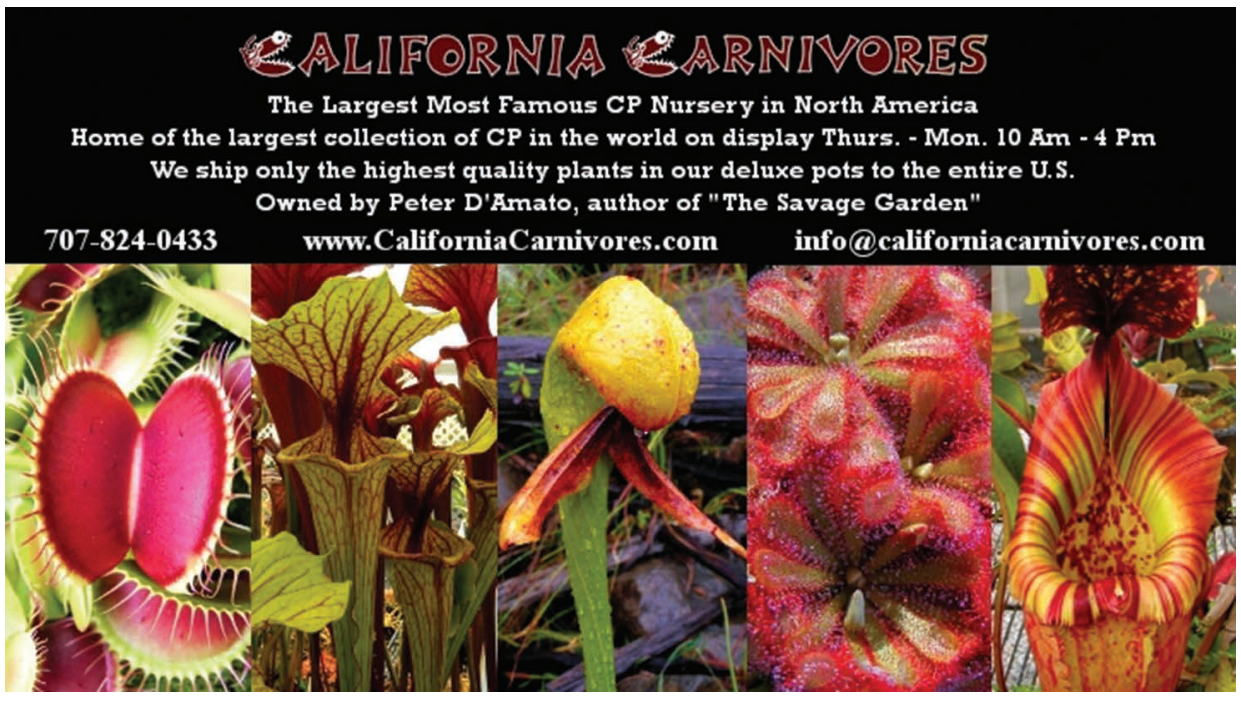

